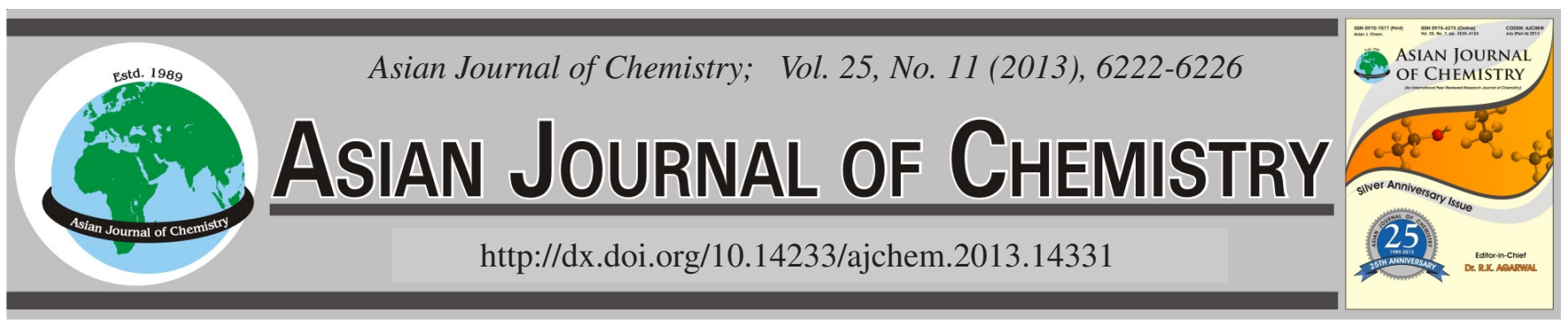

\title{
Effect of Ultrasonic Treatment on the Solubility of Sodium Sulphate Using Response Surface Methodology
}

\author{
Hui Li ${ }^{1,2}$, Guisheng ZenG ${ }^{1,2, *}$ and XinMAN Tu ${ }^{1,2}$
}

${ }^{1}$ Key Laboratory of Jiangxi Province for Persistant Pollutants Control and Resources Recycle, Nanchang Hangkong University, Nanchang 330063 , P.R. China

${ }^{2}$ School of Environment and Chemical Engineering, Nanchang Hangkong University, Nanchang 330063, P.R. China

*Corresponding author: Tel: +86 791 83953377; E-mail: zengguisheng@hotmail.com; 594271184@qq.com

\begin{abstract}
The effect of ultrasonic treatment on the solubility of sodium sulphate was investigated in this study. The influence of several single-factor experiments including temperature, ultrasonic time, ultrasonic power and rotation rate on the solubility of sodium sulphate was carried out. Response surface methodology (RSM), based on a three level, three variable central composite design (BBD), was employed to obtain the best possible combination of temperature $\left(\mathrm{X}_{1}\right)$, ultrasonic time $\left(\mathrm{X}_{2}\right)$ and ultrasonic power $\left(\mathrm{X}_{3}\right)$ for maximum solubility according to the results from single-factor experiment. The 3-D response surface plot and the contour plot was derived from the mathematical models. The results also showed that the best conditions to attain the maximum solubility are met when temperature was $35^{\circ} \mathrm{C}$, time was $20 \mathrm{~min}$, power was $140 \mathrm{w}$. Under this condition, the experimental yield was $52.6321 \mathrm{~g}$, which was well matched with the predictive yield.
\end{abstract}

Key Words: Sodium sulphate, Crystallization, Ultrasonic wave, Response surface methodology, Solubility.

\section{INTRODUCTION}

As is well known, crystallization is an attractive separation technique for manufacturing because of the advantages of low energy consumption, high efficiency and low pollution ${ }^{1}$. Crystallization out of solutions is a major separation and purification unit operation, which is applied in many fields of chemical and pharmaceutical industries. Crystallization in general can be divided into nucleation and growth. Nucleation may be compared to birth. However, before nucleus formation, the mother phase must be supersaturated or supercooled. This is the thermodynamic driving force for crystallization ${ }^{2}$. Sonocrystallization $^{3-6}$ is the use of power ultrasound to control the course of a crystallization process. Recently, sonocrystallization has received much attention. Several research groups used ultrasound to control solubility. Wang et al. ${ }^{7}$ have used ultrasound to improve the solubility of Wheat Gluten, followed in turn by pulse "on" and "off" time cycle. Laugier et al. ${ }^{8}$ have investigated the effect of ultrasound on solubility in gas-liquid systems. Jambrak et al. ${ }^{9}$ also observed the effect of ultrasound and sonication on whey proteins in order to improve their function properties. Since $\mathrm{Na}^{+}(\mathrm{aq})$ and $\mathrm{SO}_{4}{ }^{2-}$ (aq) are very common components of natural fluids, their thermodynamic properties in aqueous solution is of crucial importance in understanding various industrial and geochemical process such as crystallization ${ }^{10}$. Thus sodium sulphate was used to be the principal raw material.

Response surface methodology (RSM), which combines statistical and mathematical techniques is useful for developing, improving and optimizing processes ${ }^{11-15}$. The main advantage of response surface methodology is the reduced number of experimental trials needed to evaluate multiple parameters and their interactions. Therefore, it is less laborious and time-consuming than other approaches required to optimize a process.

Sodium sulphate was used to observe the effect of ultrasound on solubility. The objective of this study is to improve the solubility of sodium sulphate by ultrasonic using response surface methodology.

\section{EXPERIMENTAL}

Single-factor experiment: Balance method was applied to get the solubility of sodium sulphate. The solubility of sodium sulphate as target and selecting temperature $(20,30$, $40,50,60,70,80$ and $\left.90^{\circ} \mathrm{C}\right)$, time $(15,20,25,30,35,40$ and $45 \mathrm{~min})$, power $(80,100,120,140,160,180$ and $200 \mathrm{w})$ and rotational velocity $(200,300,400,500,600$ and $700 \mathrm{r} / \mathrm{min})$ as single-factor.

Design of statistical experiments: After determining the preliminary range of solubility through single-factor test, a three-level-three-factor, Box-Behnken factorial design (BBD) ${ }^{16}$ 
was adopted in this optimization study. Temperature $\left(\mathrm{X}_{1}\right)$, time $\left(\mathrm{X}_{2}\right)$, power $\left(\mathrm{X}_{3}\right)$ were the independent variables selected to be optimized for the solubility of sodium sulphate. The range of independent variables and their levels were presented in Table-1. Solubility (s) was taken as the response for the combination of the independent variables given in Table-2. Analysis of the experiment design and calculation of predicted data were carried out by using Design-expert Software 7.1.3 to estimate the response of the independent variables.

\begin{tabular}{|c|c|c|c|c|}
\hline \multicolumn{5}{|c|}{$\begin{array}{l}\text { TABLE-1 } \\
\text { INDEPENDENT VARIABLES AND THEIR LEVELS }\end{array}$} \\
\hline \multirow{2}{*}{\multicolumn{2}{|c|}{ Independent variables }} & \multicolumn{3}{|c|}{$\begin{array}{c}\text { Levels } \\
\end{array}$} \\
\hline & & -1 & 0 & 1 \\
\hline Temp & ature $\left(\mathrm{X}_{1}\right)\left({ }^{\circ} \mathrm{C}\right)$ & 20 & 30 & 40 \\
\hline Time & $\left.\mathrm{X}_{2}\right)(\mathrm{min})$ & 15 & 20 & 25 \\
\hline Powe & $\left.\mathrm{X}_{3}\right)(\mathrm{w})$ & 100 & 120 & 140 \\
\hline \multicolumn{5}{|c|}{$\begin{array}{c}\text { TABLE-2 } \\
\text { BOX-BEHNKEN EXPERIMENTAL DESIGN } \\
\text { AND RESULTS FOR SOLUBILITY } \\
\end{array}$} \\
\hline No. & $\mathrm{X}_{1}$ (temperature) & $\mathrm{X}_{2}$ (time) & $\mathrm{X}_{3}(\mathrm{w})$ & Solubility $(\mathrm{g})$ \\
\hline 1 & 1 & 0 & 1 & 49.6587 \\
\hline 2 & 1 & -1 & 0 & 49.4631 \\
\hline 3 & -1 & 1 & 0 & 25.1603 \\
\hline 4 & 0 & 0 & 0 & 50.0395 \\
\hline 5 & -1 & -1 & 0 & 25.5767 \\
\hline 6 & 0 & -1 & -1 & 46.7411 \\
\hline 7 & 0 & 0 & 0 & 50.2680 \\
\hline 8 & 0 & 0 & 0 & 49.4450 \\
\hline 9 & 0 & -1 & 1 & 49.1482 \\
\hline 10 & 0 & 1 & 1 & 50.7356 \\
\hline 11 & -1 & 0 & 1 & 26.6351 \\
\hline 12 & 0 & 1 & -1 & 50.5951 \\
\hline 13 & 0 & 0 & 0 & 49.6269 \\
\hline 14 & 0 & 0 & 0 & 50.5756 \\
\hline 15 & -1 & 0 & -1 & 30.0374 \\
\hline 16 & 1 & 1 & 0 & 48.4399 \\
\hline 17 & 1 & 0 & -1 & 49.1540 \\
\hline
\end{tabular}

\section{RESULTS AND DISCUSSION}

Effect of temperature on the solubility: Temperature is an important factor that could influence the solubility of sodium sulphate. Firstly, solubility curve was obtained without ultrasound. Then the effect of ultrasonic temperature on solubility was investigated when time is $20 \mathrm{~min}$, power $120 \mathrm{w}$, rotational velocity is $300 \mathrm{r} / \mathrm{min}$. From Fig. 1, it is found that the solubility increased as temperature ascended from $20-40^{\circ} \mathrm{C}$, highest at ca. $35^{\circ} \mathrm{C}$ and no longer increased when the temperature exceeded $40^{\circ} \mathrm{C}$. On the other hand, obviously ultrasound can increase solubility, but can not change the change trend. Ultrasound did improve the solubility and play an important role in crystallization process ${ }^{17,18}$.

Effect of time on the solubility: Different ultrasound time from 15-45 min can also affect the solubility of sodium sulphate. Solubility increased along with the extension of time. When time was over $40 \mathrm{~min}$, solubility would not have change obviously. The results were listed in Fig. 2.

Effect of power on the solubility: A higher power also presents a positive effect on the solubility of sodium sulphate.

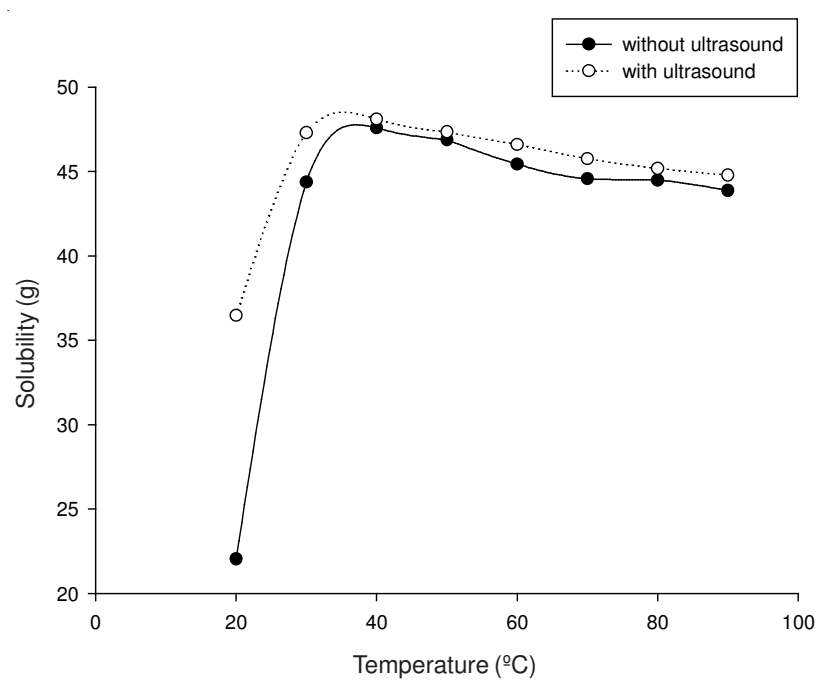

Fig. 1. Effect of temperature on the solubility with ultrasound and without ultrasound

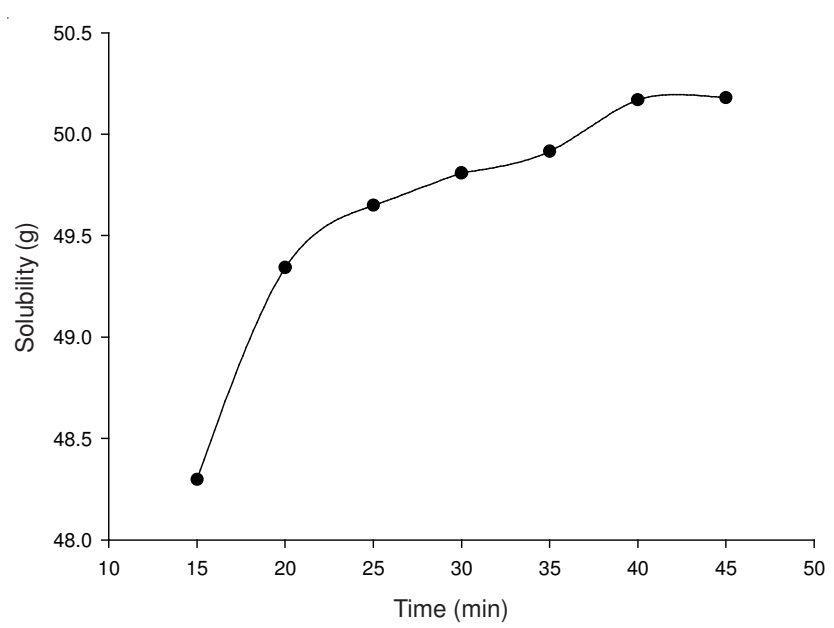

Fig. 2. Effect of time on the solubility

The solubility of sodium sulphate affected by different power is shown in Fig. 3. When the other three factors (temperature, time, rotational velocity) were $35^{\circ} \mathrm{C}, 20 \mathrm{~min}, 300 \mathrm{rpm}$, respectively. It showed that the solubility increased as the power ascended from 80-140 w. After this point, the solubility started to maintain a dynamic equilibrium with the increasing of power and no longer increased when power exceeded $140 \mathrm{w}$.

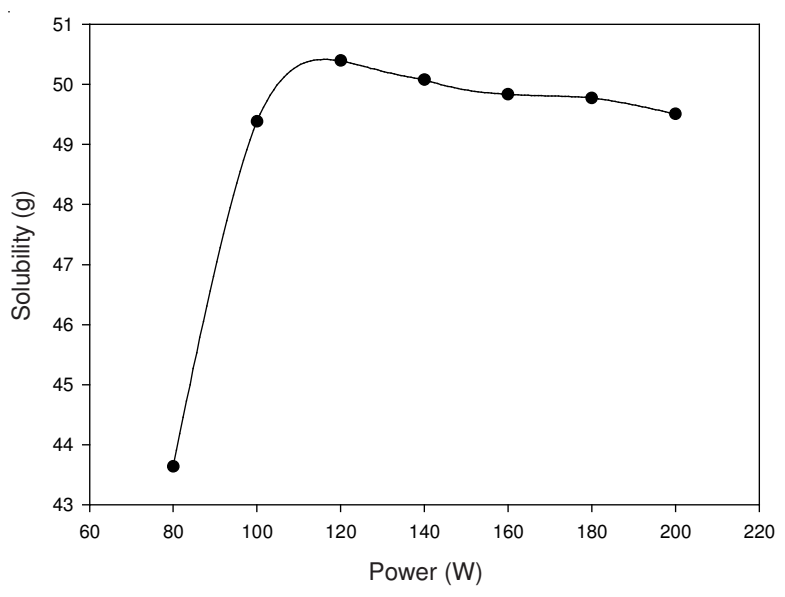

Fig. 3. Effect of power on the solubility 
Effect of rotational velocity on the solubility: Fig. 4 shows a wavy line that the effect of rotational velocity on the solubility has no significant change. Therefore it need not consider this factor when solubility is studied in the future.

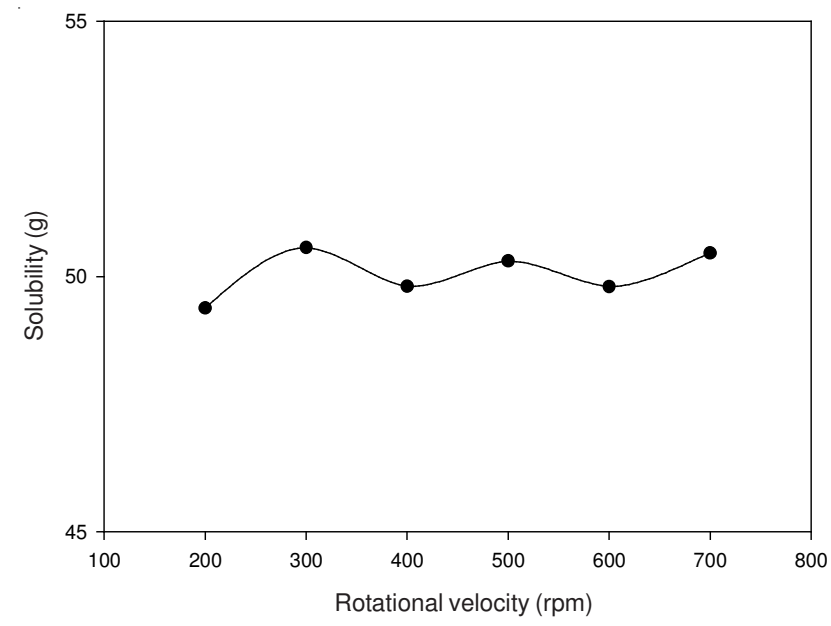

Fig. 4. Effect of rotational velocity on the solubility

Statistical analysis and model fitting: A multiple regression analysis of data was carried out to calculate the coefficients of the second order polynomial equation ${ }^{19}$ proposed to correlate the response to the three parameters:

$$
\mathrm{S}=\mathrm{k}_{0}+\sum_{\mathrm{i}=1}^{3} \mathrm{k}_{\mathrm{i}} \times \mathrm{X}_{\mathrm{i}}+\sum_{\mathrm{i}=1}^{3} \mathrm{k}_{\mathrm{ii}} \times \mathrm{X}_{\mathrm{i}} \mathrm{X}_{\mathrm{i}}+\sum_{\mathrm{i}<\mathrm{j}}^{3} \mathrm{k}_{\mathrm{ij}} \times \mathrm{X}_{\mathrm{i}} \mathrm{x}_{\mathrm{j}}
$$

By applying multiple regression analysis on the experimental datas, the following second order polynomial equation was found:

$$
\begin{array}{r}
S=+49.99100+11.16327 X_{1}+0.50023 X_{2}-0.043750 X 3- \\
0.15170 X_{1} X_{2}+0.97675 X_{1} X_{3}-0.56665 X_{2} X_{3}-11.63235 X_{1}^{2} \\
-1.19865 X_{2}^{2}+0.51265 X_{3}^{2}(2)
\end{array}
$$

where $\mathrm{S}$ is the predicted response; $\mathrm{X}_{1}, \mathrm{X}_{2}, \mathrm{X}_{3}$ are coded values of temperature, time and power, respectively.

The ANOVA data were analyzed to evaluate the significance of the different models equations associated with models parameters established by regression calculations to fit all of the polynomial models to the selected response. Table3 sums up the test of significance for regression coefficient. The model F-value of 90.59 implies the model is significant. Values of "Prob > F" less than 0.0500 indicate model terms are significant. The "Lack of Fit F-value" of 20.01 implies the lack of fit is significant. The temperature is significant. No interaction among the parameters is significant. The order of influencing solubility that can be saw from Table- 3 is: temperature $>$ time $>$ power. One top of that, the $\mathrm{R}^{2}$ values were $99.15 \%$, confirming the excellent accuracy of the model in predicting the solubility.

Optimization of solubility of sodium sulphate: Response surface optimization is more advantageous than the traditional single parameter optimization in that it saves time space and raw material. The $3 \mathrm{D}$ response surface plots described by the regression model were drawn to illustrate the effects of the independent variables and the interactive effects of each independent variable on the response variables. The shape of

\begin{tabular}{ccccc}
\multicolumn{5}{c}{ TABLE-3 } \\
\multicolumn{5}{c}{$\begin{array}{c}\text { REGRESSION COEFFICIENTS OF } \\
\text { THE PREDICTED SOLUBILITY }\end{array}$} \\
\hline Source & $\begin{array}{c}\text { Sum of } \\
\text { squares }\end{array}$ & $\begin{array}{c}\text { Mean } \\
\text { square }\end{array}$ & F-Value & P-Value \\
\hline Modle & 1587.91 & 176.43 & 90.59 & $<0.0001$ \\
$\mathrm{X}_{1}$ & 996.95 & 996.95 & 511.87 & $<0.0001$ \\
$\mathrm{X}_{2}$ & 2.00 & 2.00 & 1.03 & 0.3444 \\
$\mathrm{X}_{3}$ & 0.015 & 0.015 & $7.862 \mathrm{E}-003$ & 0.9318 \\
$\mathrm{X}_{1} \mathrm{X}_{2}$ & 0.092 & 0.092 & 0.047 & 0.8341 \\
$\mathrm{X}_{1} \mathrm{X}_{3}$ & 3.82 & 3.82 & 1.96 & 0.2043 \\
$\mathrm{X}_{2} \mathrm{X}_{3}$ & 1.28 & 1.28 & 0.66 & 0.4435 \\
$\mathrm{X}_{1}{ }^{2}$ & 569.73 & 569.73 & 292.52 & $<0.0001$ \\
$\mathrm{X}_{2}{ }^{2}$ & 6.05 & 6.05 & 3.11 & 0.1214 \\
$\mathrm{X}_{3}{ }^{2}$ & 1.11 & 1.11 & 0.57 & 0.4756 \\
\hline
\end{tabular}

the corresponding contour plots indicates whether the mutual interactions between the independent variables are significant or not ${ }^{20,21}$. Fig. 5a-b shows the 3D plot and contour plot of the effect of the independent variables temperature and time on solubility. Fig. 6a-b depicts the 3D plot and contour plot, showing the effects of temperature and power on the solubility. Fig. 7a-b shows the 3D plot and contour plot of the effect of the independent variables time and power on solubility.

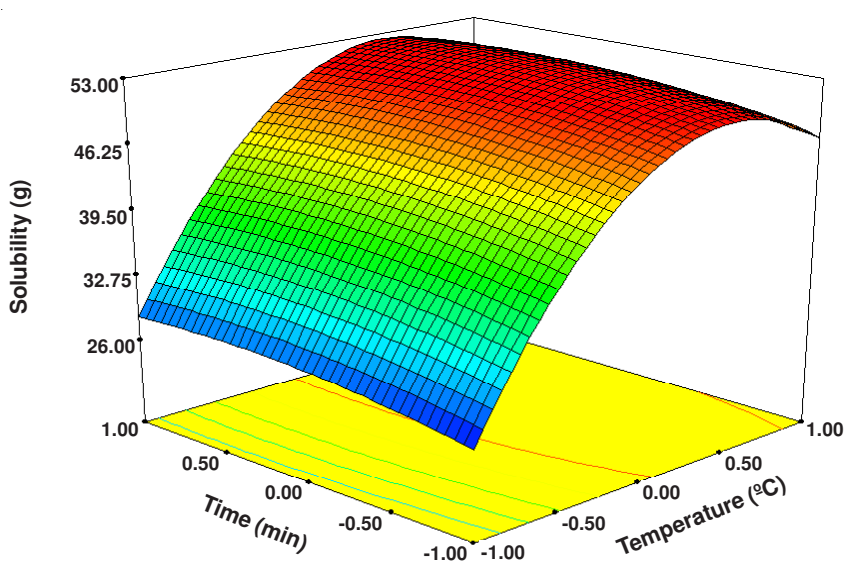

(a)

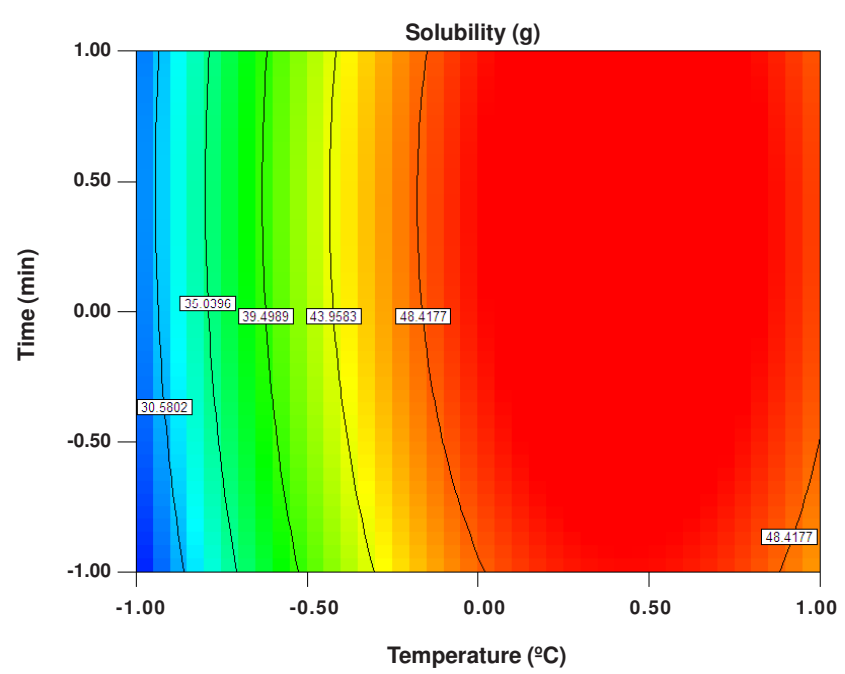

(b)

Fig. 5. 3D plot and contour plot of the effect of the independent variables temperature and time on solubility 


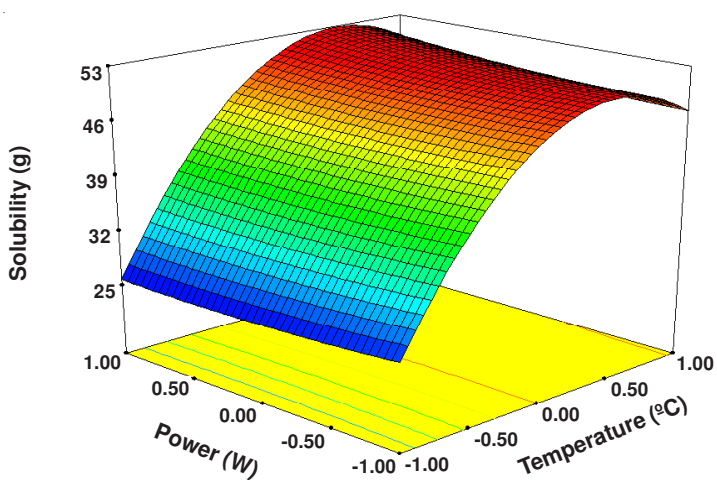

(a)

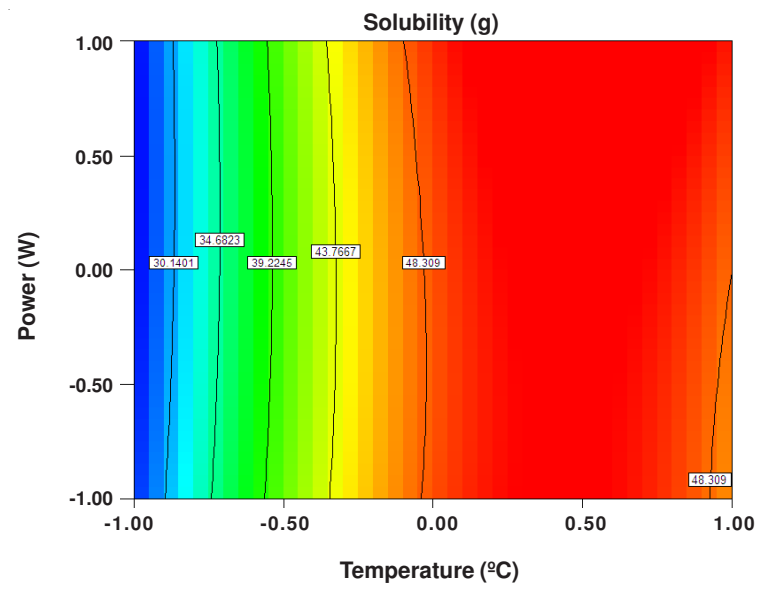

(b)

Fig. 6. 3D plot and contour plot of the effect of the independent variables temperature and power on solubility

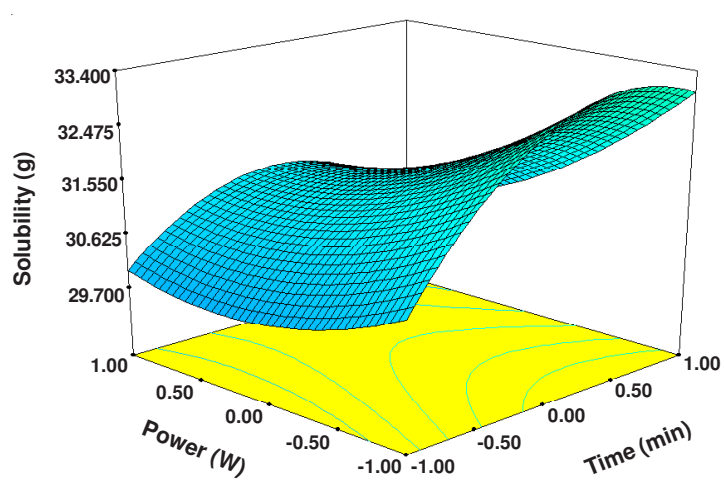

(a)

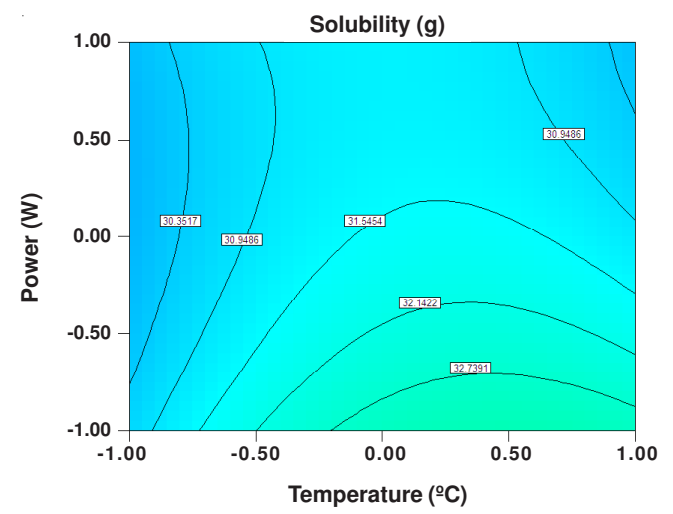

(b)

Fig. 7. 3D plot and contour plot of the effect of the independent variables time and power on solubility
Fig. 5a-b shows that the solubility yield was maximal when temperature was 34.3 to $36^{\circ} \mathrm{C}$ during from 18.4 to $20 \mathrm{~min}$. By using eqn. 2 , the maximum solubility was obtained at $35.2^{\circ} \mathrm{C}$ and with the time of $19.7 \mathrm{~min}$. This evidences that the solubility increased at a minimum time when raised the temperature. Fig. 6a-b shows the solubility yield was maximal that when temperature was 34.3 to $36^{\circ} \mathrm{C}$ during from 120 to $140 \mathrm{w}$. The maximum solubility was obtained at $35.2{ }^{\circ} \mathrm{C}$ and $140 \mathrm{w}$. We can also obtain the maximum solubility.

The response surface methodology allowed us to simulate the effect of temperature, time and power on solubility. The following operating conditions: $19.7 \mathrm{~min}$, at $35.2^{\circ} \mathrm{C}$ with a power of $140 \mathrm{w}$ were selected in order to combine optimized solubility, and solubility is $53.6318 \mathrm{~g}$.

Verification of the models: The suitability of the model equation for predicting the optimum response values was tested by using the selected optimal conditions. The maximum predicted yield and experimental yield of solubility were given in Table- $4^{22}$. Additional experiment by using the predicted optimum conditions for solubility was carried out: temperature of $35.2{ }^{\circ} \mathrm{C}$, time of $19.7 \mathrm{~min}$, power of $140 \mathrm{w}$. To ensure the predicted result was not biased toward the practical value, experiment rechecking was performed by using these modified optimal conditions: temperature of $35^{\circ} \mathrm{C}$, time of $20 \mathrm{~min}$, power of $140 \mathrm{w}$. The solubility of $53.5926 \mathrm{~g}$ was obtained, demonstrated the validation of the RSM model. The results of analysis confirmed that the response model was adequate for reflecting the expected optimization (Table-4) and the model of eqn. 2 was satisfactory and accurate.

\begin{tabular}{ccccc}
\multicolumn{5}{c}{ TABLE-4 } \\
PREDICTED AND EXPERIMENTAL VALUES OF THE \\
RESPONSE AT OPTIMUM AND MODIFIED CONDITIONS \\
\hline & $\begin{array}{c}\text { Temp. } \\
\left({ }^{\circ} \mathrm{C}\right)\end{array}$ & $\begin{array}{c}\text { Time } \\
(\mathrm{min})\end{array}$ & $\begin{array}{c}\text { Power } \\
(\mathrm{w})\end{array}$ & $\begin{array}{c}\text { Yield of } \\
\text { solubility }(\mathrm{g})\end{array}$ \\
\hline Optimum conditions & 35.2 & 19.7 & 140 & 53.6318 \\
Modified conditions & 35 & 20 & 140 & 52.6321 \\
\hline
\end{tabular}

\section{Conclusion}

The effect of ultrasonic irradiation on the solubility of sodium sulphate was studied. Ultrasound can increase solubility, but can not change the trend. Ultrasound did improve the solubility and play an important role in crystallization process. Based on the single-factor experimental, RSM was used to estimate and optimize the experimental variables: temperature $\left({ }^{\circ} \mathrm{C}\right)$, time ( $\left.\mathrm{min}\right)$ and power $(\mathrm{w})$. Temperature has highly significant effects on the response values. The optimal conditions for solubility was as follows: temperature of $35.2^{\circ} \mathrm{C}$, time of $19.7 \mathrm{~min}$ and power of $140 \mathrm{w}$. Under these conditions, the experimental yield of solubility was $52.6321 \mathrm{~g}$, which was close with the predicted yield value.

\section{ACKNOWLEDGEMENTS}

This work was financially supported by the National High Technology Research and Development Program of China (2010AA065204), the National Natural Science Foundation of China (51266011) and the Jiangxi Provincial Department of Education(GJJ13505). 


\section{REFERENCES}

1. J.K. Wang, Int. Acad. Dev., 5, 37 (2002).

2. M.L. Herrera, M.L. Gatti and R.W. Hartel, Food Res. Int., 32, 289 (1999).

3. A. Kirdylla, T. Krawczyk, F. Tumakaka and G. Schembecker, Chem Eng. Sci., 64, 1635 (2009).

4. W.S Chen and G.C Huang, Ultrason. Sonochem., 15, 909 (2008).

5. M.D.L Castro and F.P Capote, Ultrason. Sonochem., 14, 717 (2007).

6. L. Boels, R.M. Wagterveld and G.J. Witkamp, Ultrason. Sonochem. 18, 1225 (2011).

7. W.J Wang, H.R Bao and H. Xu, Inst. Food Sci., 30, 72 (2009).

8. F. Laugier, C. Andriantsiferana, A.M. Wilhelm and H. Delmas, Ultrason. Sonochem., 15, 965 (2008)

9. A.R. Jambrak, T.J. Mason and V. Lelas, J. Food Eng., 86, 281 (2008).

10. P. Marliacy, J.B. Bouredt, L. Schuffenecker and R. Solimando, J. Chem. Thermodyn., 34, 579 (2002).

11. M.S. Tanyildizi, D. Ozer and M. Elibol, Process Biochem., 40, 2291 (2005).
12. J. Cescut, E. Severac, C.M. Jouve and J.L. Uribelarrea, J. Chromatogr. A, 1218, 373 (2011).

13. C.S. Hsieh, H. Zhu, T.Y. Wei, Z.J. Chung, W.D. Yang and Y.H. Ling, J. Eur. Ceram. Soc., 28, 1177 (2008).

14. T.H. Hou, C.H. Su and W.L. Liu, Powder Technol., 173, 153 (2007).

15. B.T. Lin, M.D. Jean and J.H. Chou, Int. J. Adv. Manuf. Technol., 34, 307 (2007)

16. X.L. Yin, Q.H. You and Z.H. Jiang, Carbohydr. Polym., 86, 1358 (2011).

17. H. Tang, Z.D. Sun, Z.H. Xu and Z.C. Wei, Inst. Food Sci., 29, 368 (2008).

18. C.H. Zhang and X.Y. Song, China Oils Fats, 36, 30 (2011).

19. Y.L. Pang, A.Z. Abdullah and S. Bhatia, Chem. Eng. J., 166, 873 (2011).

20. Y. Li, F.J. Cui, Z.Q. Liu, Y.Y. Xu and H. Zhao, Enzyme Microbial Technol., 40, 1381 (2007).

21. C.Y. Gan and A.A. Latiff, Food Chem., 124, 1277 (2011).

22. Y.F. Zou, X.F. Chen, W.Y. Yang and S. Liu, Carbohydr. Polym., 84, 503 (2011). 